\title{
Sidescan sonar meets airborne and satellite remote sensing: challenges of a multi-device seafloor classification in extreme shallow water intertidal environments
}

\author{
R. M. Capperucci ${ }^{1}$ (D) A. Kubicki ${ }^{2}$ P. Holler ${ }^{1}$ A. Bartholomä ${ }^{1}$
}

Received: 3 May 2019 / Accepted: 28 January 2020 / Published online: 12 February 2020

(C) The Author(s) 2020

\begin{abstract}
Tidal ecosystems like the Wadden Sea are particularly valuable for their ecological and economic importance. Here, the natural dynamics of the abiotic and biotic processes is threatened by the human pressure, and great efforts are made on mapping and monitoring programs. Remote sensing techniques (e.g., satellite and airborne sources) are commonly used on land and intertidal areas, whereas hydroacoustic devices are deployed in the subtidal zones. The overlap of hydroacoustics (sidescan sonar) and airborne Lidar data in such sensitive transitional zone (inter- to subtidal) is rather uncommon. In order to test the limitations of both techniques in extremely shallow waters $(0.7 \mathrm{~m} \mathrm{~min}$, water depth) and to find the most efficient methods for the spatial classification of intertidal areas, a portion of the backbarrier tidal flat of Norderney was investigated. Lidar bathymetric data were used for extracting high resolution morphological information. Sidescan sonar mosaics were collected in two following years under contrasting weather conditions. An expert classification based on sidescan sonar backscatter intensity, seafloor texture, morphology, and surface sediment data subdivided the research area into 10 classes. The outcomes were compared with an existing RapidEye-based classification. The tested methods showed both advantages and limitations, which were discussed based on statistical analyses. Satellite and Lidar approaches were most suitable for mapping biogenic features (e.g., shellfish beds) over large areas, whereas sidescan sonar was superior for detail detection and discrimination of morpho-sedimentary regions. As an outlook, it is postulated to perform ground-truthed hydroacoustic mapping on small testing areas, and to use the obtained classification for training satellite-based classification algorithms.
\end{abstract}

\section{Introduction}

Coastal environments represent the interface between land and sea (Carter 1988), each of these characterized by specific morpho-dynamic processes (Hinrichsen 1998). The coast is the place where some of these processes interact, increasing the complexity of such ecosystem and the parameters to be taken into account in order to describe it. Despite being accounted among the most diverse natural habitats on earth (Gopal et al. 2000), coastal ecosystems are undermined by multiple factors, mostly related to the human presence (e.g.,

R. M. Capperucci

ruggero.capperucci@ senckenberg.de

1 Senckenberg am Meer, Südstrand 40, 26382 Wilhelmshaven, Germany

2 Geo Ingenieurservice Nord-West GmbH \& Co. KG, Kutterstr. 3, 26386 Wilhelmshaven, Germany
McLachlan and Brown 2006), due to their strategic economic value. The increased general awareness about concepts like habitat loss, biodiversity, and human impact, led in the last 30 years to political actions in order to guarantee the protection of the most endangered ecosystems, specifically with national and international mapping and monitoring programs (e.g., ICES 2014). Any activity aiming to preserve a habitat has to face one fundamental task: the definition of specific sets of measurable parameters, which are able to simplify the natural complexity and, still, to realistically and reliably describe the habitat. Once the status quo of a habitat has been proved, a monitoring program can account for modifications in the sets of parameters.

Many tools are available to approach such tasks. Among them, the correct application of remote sensing techniques in long-term programs of habitat mapping and monitoring, particularly for vulnerable ecosystems, assumed a central role in supporting land-use decision making.

Tidal driven coasts clearly express such a dynamic equilibrium of a transition zone between land and sea, being 
characterized by long-term stable geomorphologies and shortterm transport processes. The world nature heritage "Wadden Sea," in the southern North Sea, is one of such dynamic and diverse ecosystems, with a high economic and ecological value (Park et al. 2010; Van der Wal and Herman 2007). Tides, waves, human activities (such as fisheries, land reclamation works, tourism, etc.), and extreme weather events shape the tidal flat environment constantly. Therefore, a selection of time- and cost-efficient methods for large-scale coastal mapping and monitoring is required (van Beijma et al. 2014).

Because of their ecological relevance, specific programs have been undertaken for detecting changes in the biotic and abiotic characteristics of the tidal flats in the Wadden Sea (e.g., shifts in sediment composition and/or in the biocommunities), and in order to point out potential loss of the natural or seminatural habitats. Such a diversity of issues requires a variety of in situ measurements, which are in turn strongly affected by the limited accessibility of tidal flats (Park et al. 2010). In this context, the implementation of remote sensing techniques represents a great advantage.

Since decades, multispectral remote sensing by means of satellite and airborne imaging systems represents a costefficient method for spatial mapping and monitoring on land. However, its use in mapping intertidal habitats presents still strong limitations. Satellite data (TerraSAR, SAR) have been used in the Wadden Sea - alone or in combination with other remote sensing sources - for detecting morphological changes (e.g., bedform shift, Adolph et al. 2017a, b; tidal channel movements, Adolph et al. 2018) and for the definition and contouring of shellfish beds (Adolph et al. 2018). Most of the studies focused on the discrimination of the three main components of a backbarrier tidal system: the water surface, the shellfish beds, and the tidal flat deposits, without any closer look into the sediment composition and distribution. Müller et al. (2016) investigated the presence, while Gade et al. (2008) used the presence of ripples on SyntheticAperture Radar (SAR) data as a surrogate for mapping sandy sediments. Jung et al. (2015) tried to differentiate the tidal deposits, using a combination of SAR and RapidEye (RE) multispectral data. Excluding the water surface and the unclassified area, he successfully distinguished four sediment classes: mud, mixed sediments, wet sand, and dry sand.

The most modern Lidar technique (Light detection and ranging) has also been implemented to intertidal monitoring (Shan and Toth 2018). Lidar devices are airborne remote sensing tools, which provide high-precision bathymetry and backscatter intensity data of extensive areas in a short time and at a reasonable cost. The Lidar technology presents the advantage to be largely independent from the weather (e.g., cloud coverage) and sea conditions (as the flight takes place during low tide), although its main limitation is given by the water level, which in case of adverse weather can high-stand on the tidal flat even during low tides. The application of dual frequency systems (red and green laser) to increase the light penetration in the water column is strongly limited in the Wadden Sea area, where the high amount of fine sediments in suspension in the water column (up to $120 \mathrm{mg} / \mathrm{l}$, e.g., Badewien et al. 2009; Bartholomä et al. 2009) limit the light penetration to $<0.5 \mathrm{~m}$ (Staneva et al. 2009). Nevertheless, Lidar data have been used for the automatic detection of water surfaces and for extracting the land-water boundaries in the Wadden Sea region (Schmidt et al. 2013). The attempt to resolve more elements was limited to the identification of the intertidal areas, namely mudflats (Schmidt et al. 2012; Schmidt et al. 2019).

Among other remote sensing systems, hydroacoustic devices are standard underwater tools for seafloor classification and habitat mapping. In particular, sidescan sonars (SSS) are versatile systems, which can be deployed in different water ranges, as their lateral ability to investigate the seafloor (swath) is independent from the water depth.

They have been used successfully on various substrates (e.g., Collier and Brown 2005; Bartholomä 2006; Holler et al. 2017; Heinrich et al. 2016). However, SSS have been poorly used in extreme shallow water tidal ecosystems, where other remote sensing sources offered a faster and broader coverage. Existing application of SSS to intertidal environments were usually limited to the lower intertidal-subtidal interface. Degraer et al. (2008) explored the ability of SSS to detect biogenic reefs along the Belgian coast, while Rahnemoonfar et al. (2018) focused on the automatic identification of seagrass. In the Wadden Sea region, van Overmeeren et al. (2009) used the SSS for mapping mussel banks in the tidal flat.

Effectiveness can be defined as the ability to accomplish a task, achieving the intended results (Cambridge University Press 2014). Efficiency is the most convenient way to do that. Systems can be effective, but not efficient, depending on the task. The same applies also to remote sensing techniques, with the effectiveness and efficiency strictly depending on the goal. The detection of a shellfish bed, for example, can be efficiently achieved by applying suitable automatic algorithms on very large datasets of remote sensing records (e.g., Schill et al. 2006; NOAA Coastal Services Center 2003 for an overview of automatic and expert-based classification methods). However, if the goal is to find out the seasonal growing rate of such shellfish beds, that approach will probably not be effective, because of the filtering-coarsening-interpolating steps connected to the automatic classification. On the other hand, the manual contouring of shellfish beds on SSS data could give an unpaired effectiveness, but with a scarce efficiency if the goal is the mapping of the entire Wadden Sea.

The combination of SSS and Lidar data is rather uncommon, although recommended by some authors (e.g., Schmidt et al. 2019), as the main limiting factor for the Lidar is the presence of water, which is the mean for collecting SSS data. On the other hand, SSS can be operated only during specific time windows (high tide) and using limited swath (a few 
hundred meters, maximum), and therefore only small areas can be surveyed within a single high tide. The transition intertidal-subtidal, hence, represents the zone where both the technologies show some limitations.

For the present research, a SSS was deployed in the intertidal flat of Norderney (German Wadden Sea) in extremely shallow water conditions (up to $0.7 \mathrm{~m}$ water depth) in order to check the feasibility of using acoustic data for seafloor characterization on tidal flats. The data were combined with bathy/topographic information from Lidar data, and compared with an existing sediment classification performed by means of RE data (Jung et al. 2015).

\section{Physical settings}

The Island of Norderney is part of the East Frisian barrier islands, in the German Bight (southern North Sea). The Wadden Sea barrier lagoon system spans for over $480 \mathrm{~km}$ from the Netherlands (West Frisian) through the German coast (East- and North Frisian) to Denmark (North Frisian), and includes the most extensive meso-tidal environment in the world. The East Frisian back barrier depositional system is slightly ebb-dominant, with maximum flow velocity of 1.2 to $1.5 \mathrm{~m} / \mathrm{s}$ in the tidal inlets, and 0.4 to $0.5 \mathrm{~m} / \mathrm{s}$ on the tidal flats (e.g., Joerdel et al. 2002; Stanev et al. 2007; Bartholomä et al. 2009; Staneva et al. 2009). The water mass movement also acts as the main source of nutrients for suspension feeders, which are an important source for fine-grain deposits (e.g., Bartholomä et al. 2000; Delafontaine et al. 2000).

The recent position and shape of Norderney is the result of the deposition of mobile sediments on a Pleistocene palaeorelief (Saalian and Weichselian glacial/periglacial deposits) following the sea level rise over the last 6500 years (Streif 1990). The early deposits acted as a sediment trap, leading to the development of large eolian dunes, which are still the signature landscape of the islands (Oost et al. 2012).

The island of Norderney extends west-eastfor $14 \mathrm{~km}$. The Riffgat channel (Fig. 1) separates Norderney from the island of Juist on the western side, whereas the Ostbalje tidal inlet divides it from the island of Baltrum on the eastern side. Both inlets cut through the tidal flat, parallel to the coastline of the island, and merge in the Norderney Wattfahrwasser (watershed), which, depending on the tidal conditions, is a navigable waterway for small boats. The tidal inlet connects the catchment area with the open North Sea, and the tidal prism controls its size (Walter 1972). The mean tidal range in the Riffgat channel is of $2.4 \mathrm{~m}$ (Dörjes et al. 1986), with maximum amplitudes up to $3.2 \mathrm{~m}$ during spring tides. The channel is ebbdominated, as the westward ebb current reaches slightly higher speeds than the eastward flood current. During both tidal phases, the current velocity typically exceeds $1 \mathrm{~m} / \mathrm{s}$ (Stanev et al. 2003).

The Riffgat branches into several secondary channels; one of them (named Wagengat, Fig. 1) borders from west a large sandbank called Lütetsburger Plate, which is the research area of the present study. This Lütetsburger Plate region is extremely shallow, with depths from $-6.5 \mathrm{~m}$ (depth referred to Chart Datum $=$ LAT, Lowest Astronomical Tide) close to the Riffgat channel to the $+2.2 \mathrm{~m}$ in the shallowest regions.

Altogether, the backbarrier tidal area between the island of Norderney and the mainland covers over $72 \mathrm{~km}^{2}$, with a typical sequence of subtidal to supratidal deposits: salt marshes, mud flat, mixed flat, sand flat, and subtidal gullies and channels (Reineck and Singh 1980; Flemming 2012). The sediment composition covers the whole spectrum of mud, sand, and gravel mixture, with the fine fractions (clay, silt, and sand) particularly dominant. Changes in the sediment composition are gradual (e.g., Bartholomä and Flemming 2007) and therefore challenging for any kind of investigation aiming to segment, to classify, or to delineate sediment patches. The subdivision among mud-, mixed-, and sand flats takes also into account the structures and geometries of the deposits (beddings, hummocky, etc., Flemming 2012). In general, the sediments show a parallel to the coastline oriented zonation, which fines up towards the dike line (e.g., Flemming and Ziegler 1995). Such spatial distribution is controlled by tidal currents and by local wind-induced waves.

The most evident biocommunities are represented by pacific oysters, which replaced the blue mussel beds starting in the late 90s of last century. More recently, the blue mussels
Fig. 1 Location map of the study site (in orange) with the names of the main geographical and morphological units used in the text

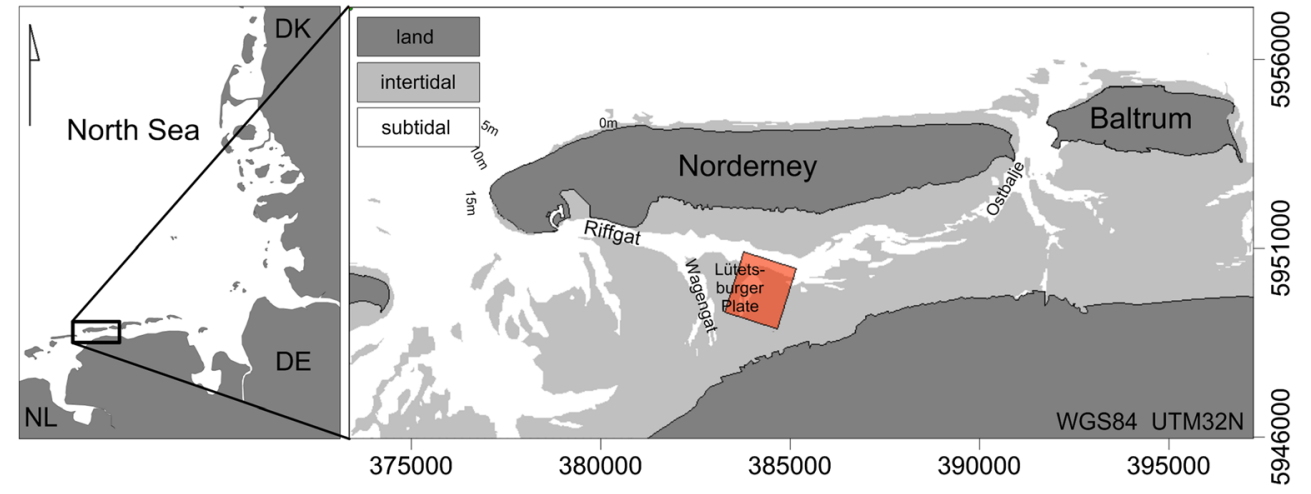


Table 1 Technical specifications of the starfish $452 \mathrm{f}$ and overview about SSS data collection and weather/sea conditions recorded during the two surveys in 2013 and 2014

\begin{tabular}{lll}
\hline Starfish 452f SSS & & \\
\hline Frequency & $450 \mathrm{kHz}$ & \\
Beam angle along track & $0.8^{\circ}$ & \\
Beam angle across track & $60^{\circ}$ & \\
Max. horizontal resolution (nominal) & $2.5 \mathrm{~cm}$ & \\
Pulse length & $400 \mathrm{~ms}$ & \\
Ping rate & $14 \mathrm{~Hz}$ & \\
Survey data & June 2013 & September 2014 \\
Number of lines & 17 & 13 \\
Swath (m) & 120 & 120 \\
Total coverage (sqm) & $2,200,000$ & $1,877,000$ \\
Av. wind speed $(\mathrm{km} / \mathrm{h})$ & 10.5 & 28.0 \\
Av. wind direction & $\mathrm{NNE}$ & $\mathrm{NNW}$ \\
Max. wind gusts $(\mathrm{km} / \mathrm{h})$ & 34.9 & 55.2 \\
Max. wave height $(\mathrm{m})$ & 0.7 & 1.2 \\
Av. wave direction & $\mathrm{N}$ & $\mathrm{NNW}$ \\
\hline
\end{tabular}

have reestablished on top of the oysters, the latter forming a new "local" hardground for the Wadden Sea area (Markert et al. 2010, 2013).

\section{Methods}

Sidescan sonar (SSS) data and surface sediment samples were collected during two surveys in June 2013 and September
2014. Since most of the area falls dry during low water, high tide windows ( $3 \mathrm{~h}$ before and after the predicted high tide) were used for the acoustic data collection; low tide windows (predicted low tide $\pm 3 \mathrm{~h}$ ) were used for sediment sampling and in situ observations (in-field description, photos, etc.). Weather and tide conditions were logged.

\section{Sidescan sonar data collection and processing}

A Starfish $452 \mathrm{~F}(450 \mathrm{kHz})$ was pole mounted on the Senckenberg work boat "Scanner" for SSS data acquisition (approx. $50 \mathrm{~cm}$ below water surface). The acoustic lines were collected at a speed between 2 and $3 \mathrm{kn}$ and the tracks were designed parallel to the main morphologies (coastline and Riffgat channel), with $120 \mathrm{~m}$ swath and $100 \mathrm{~m}$ line-spacing (Table 1). In total, 17 and 13 lines were recorded in 2013 and 2014, respectively (the lower amount of 2014 lines was due to the adverse tidal/weather conditions). A RTK-GPS Trimble SPS 852 system (base rover configuration) was deployed for RTK positioning. The data were collected starting from the lines corresponding to the deepest areas (near the Riffgat) and following the rise of the tide, till the most internal regions to the south, where the mean water depth recorded underneath the SSS was about $0.7 \mathrm{~m}$.

Data processing included geometric (offset, bottom pick, and slant range), and radiometric (Time Variable Gain, Empirical Gain Normalization table, nadir filter) corrections and was performed with the SonarWiz 7 software. A $0.5 \mathrm{~m}$ pixel-resolution mosaic was exported for the two datasets (2013 and 2014, Figs. 2 and 3). Low and high backscatter
Fig. 2 Digital Terrain ModelDTM (a) and SSS mosaic (b) of the study area. The DTM was based on Lidar data collected in 2013; the blue color corresponds to the areas covered by water during the Lidar flight. Thirty-two sediment samples (black dots, in a) were collected along 5 northsouth transects ( $\mathrm{T} 1$ to $\mathrm{T} 5$, from west to east) in 2013 (orange dots, in b) and 2014 (blue dots, in b). Two transects (T1 and T3) are highlighted (black lines) and presented in details within the text

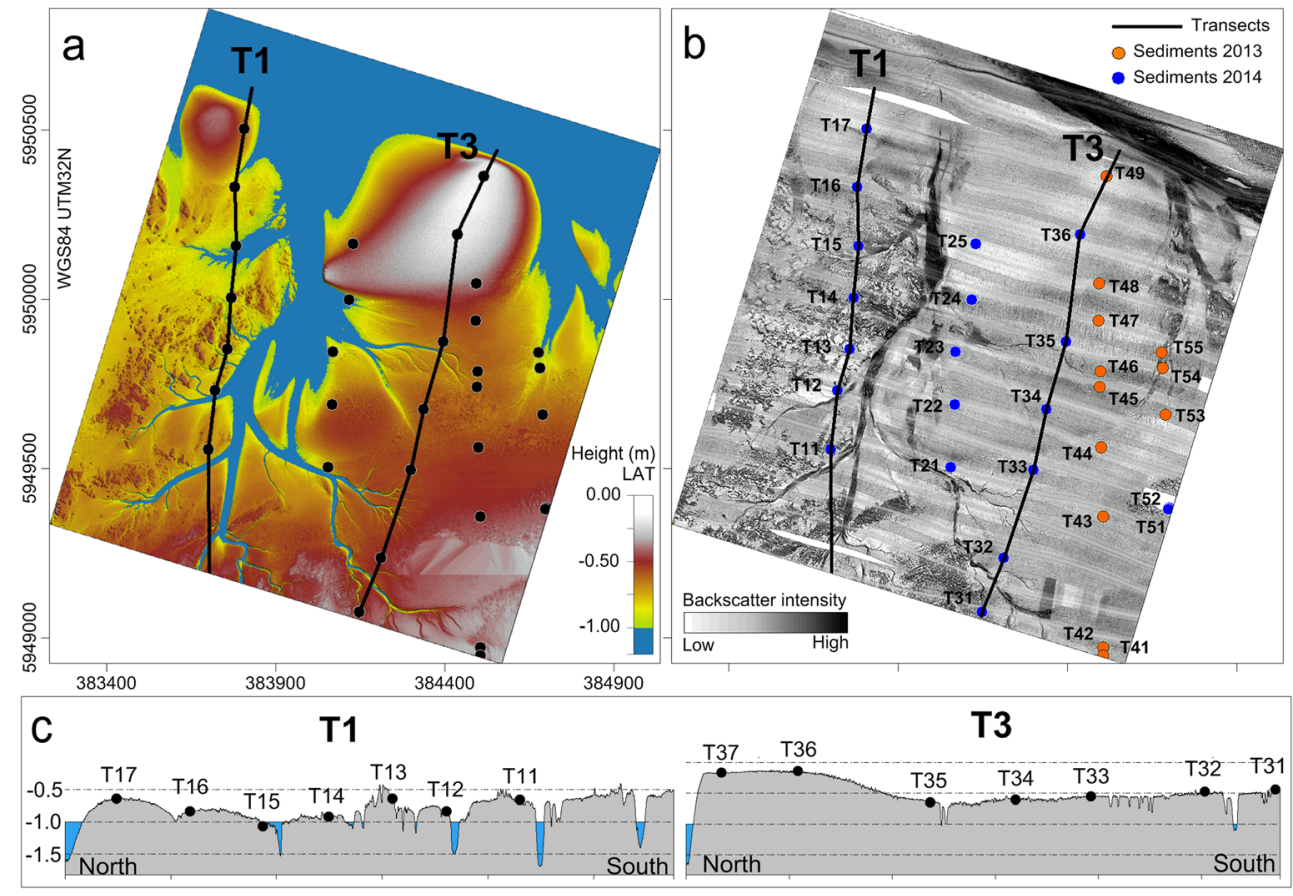




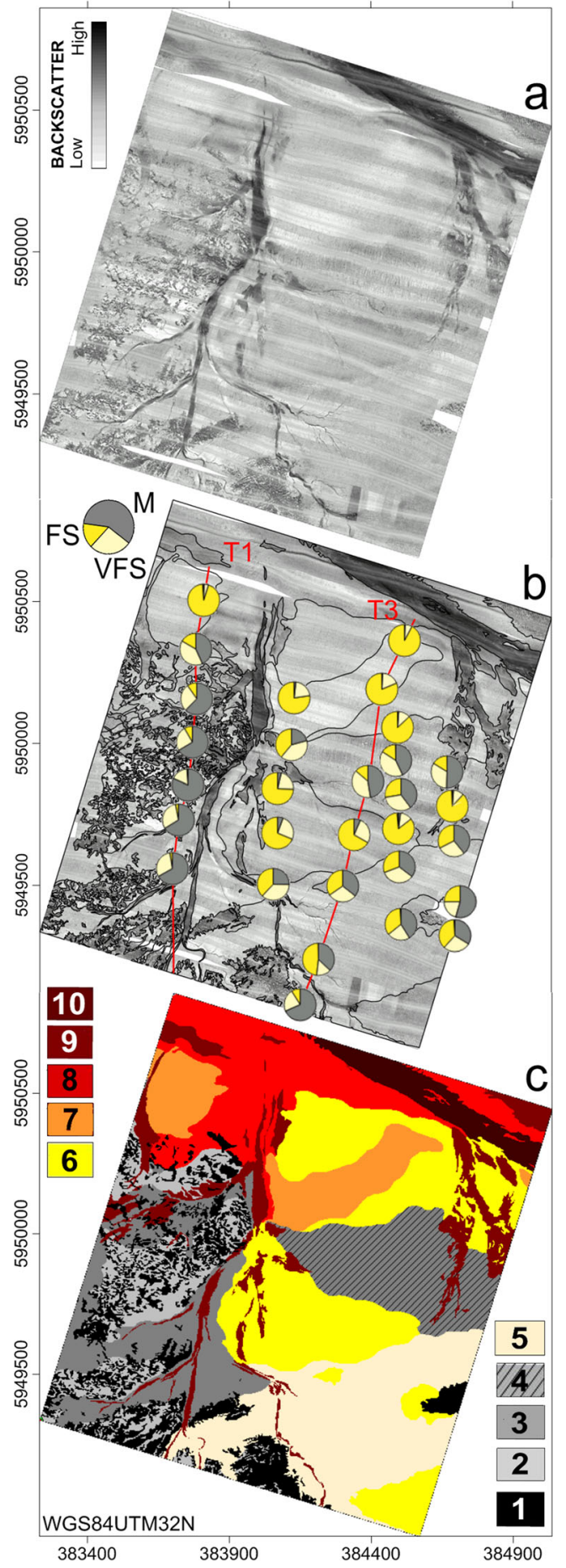

Fig. 3 Mosaic of the SSS backscatter data of 2013 (a), overlaid by the sediment composition pie charts (b). Seafloor classification of the Lütetsburgerplate based on SSS, Lidar, and sediment data (c). The pie charts were built using the three main sediment fractions (M: mud, VFS: very fine sand, FS: fine sand). Transects T1 and T3 are highlighted in red. The area was segmented into 10 classes, corresponding to different backscatter regions, seafloor textures, morphologies (bedforms, channels, etc.), and sediment characteristics. For the description of the classes, see the text values were displayed in a 256 greyscale palette (high backscatter $=$ low greyscale values $=$ darker greyscale tones; low backscatter $=$ high greyscale values $=$ lighter greyscale tones) . Due to the difference in data quality, only the 2013 mosaic was further used for the acoustic classification. The comparison between the 2013 and 2014 data was based on a reduced set of seafloor features, which could be recognized and mapped in both datasets. Additional mosaics (at $0.25 \mathrm{~m}$ and $0.125 \mathrm{~m}$ pixel-resolution) were generated for individual subregions, in order to check the ability of the system in resolving specific targets (i.e., shellfish patches, tidal gullies), and compare the results with the outcomes from different remote sensing systems.

\section{Sediment samples data collection and processing}

Surface sediment sampling and in-field observations took place along 5 transects (transect 1, T1: from station T11 to T17; transect 2, T2: from station T21 to T25, etc.), NS oriented, for a total amount of 32 stations (12 in 2013, 20 in 2014, Fig. 2). For each station, a volume of sediments between 300 and $500 \mathrm{ml}$ was scooped from the surficial layer $(\sim 1-2 \mathrm{~cm})$, labeled, described, and stored for grain size analysis. The seabottom along the Riffgat channel was not sampled during the 2013 and 2014 campaigns. However, sediment data for the western part of the Riffgat channel were available from a previous survey (September 2011).

In situ observations and sample description included a short report about the sampling location (i.e., water coverage, presence, and characteristics of bedforms and biota) and a macroscopic description of the sediments (color, grain size, sorting, stratification, presence of shells, and organisms). Where possible, photos of the sample site were taken. The positioning of the sampling locations was recorded by means of a GPS Garmin GPA72 system.

Sediment samples were processed in the Lab for grain size analysis. The preparation of the samples included osmotic desalinization of the samples, wet sieving through a $63 \mu$ mesh size for separating the mud fraction, dry sieving through a $2 \mathrm{~mm}$ mesh size for splitting the sand and gravel fractions. The sand fraction was analyzed using a MacroGranometer ${ }^{\mathrm{TM}}$ settling tube (Brezina 1979) and divided into five $1 \phi$ intervals following the nomenclature of Wentworth (Wentworth 1922, based on Udden 1914; the Udden-Wentworth scale), from very coarse sand $(-1 \leq \phi$ $<1)$ to very fine sand $(3 \leq \phi<4)$. The $1 / 4 \phi$ sediment distribution was then used for classifying the sediments into textural classes (Folk 1954), using the Gradistat Excel working sheet (Blott and Pye 2001).

The in situ macroscopic description of the sediments and of the sampling locations, together with the grain size 
results were used for improving the definition and refining the description of the acoustic-based classes.

\section{Lidar data}

Lidar (Light detection and ranging) data were collected in 2013 by The MILAN Geo Service Company, on behalf of the Lower Saxony Water Management, Coastal Defence and Nature Conservation Agency (Niedersächsischer Landesbetrieb für Wasserwirtschaft, Küsten und Naturschutz, NLWKN) over two regions of the Norderney tidal flat, one of them matching the study area of this research. Eight routes with $320 \mathrm{~m}$ spacing were designed east-west oriented. Two extra lines for calibration were collected orthogonally to the main grid. The system (a RIEGL VQ 820-G red LiDAR) was deployed from an altitude of $600 \mathrm{~m}$ and achieved a horizontal/vertical accuracy of 0.40 / $0.15 \mathrm{~m}$, respectively. The NLWKN kindly provided the dataset in $1 \mathrm{~m}$ grid size. The points were gridded in Global Mapper v15 and a DTM in $1 \mathrm{~m}$ grid size) was used for extracting the bathymetric information for defining the main morphological features. The areas corresponding to the water surface were blanked and therefore not further considered for the analysis. Within the framework of the WIMO project (Winter 2017), a second Lidar dataset was collected by the MILAN Geo Service in October 2014 (using the same Lidar system and setups), covering an area of approximately $30 \mathrm{~km}^{2}$ between the mainland the island of Norderney. The acquisition included both bathymetric and intensity (backscatter) data. However, these datasets were only partially included in the present study, specifically for a small sector, which was used for the comparison of the shellfish beds detection between the SSS and the Lidar system (Fig. 4). All the depths reported in the present study are referred to Chart Datum (Lowest Astronomical Tide, BSH 2019).

\section{Seafloor classification}

An attempt to use a semi-automatic classification approach ("SonarWiz7 Seabed Characterization" tool, Chesapeake Technology, 2017) was made on the 2013 SSS records, varying both the geometric settings (e.g., window size, window step) and the classification options (number of classes, Grey Level Co-occurrence Matrix algorithms). The final outcome, however, resulted in a "saltand-pepper" pixelized image, with any clear correlation between the acoustic classes and the physical characteristics of the seafloor (sediments and morphologies). Therefore, a combined expert-based classification approach was preferred. The $0.5 \mathrm{~m}$ SSS mosaic from the survey in 2013 was segmented into different regions (acoustic classes, manually contoured). Where present, the sharp changes in SSS backscatter intensity were used for the segmentation of the mosaic. However, most of the area presented gradual transitions in the backscatter greyscale values. In these cases, the SSS mosaic was firstly used for a coarse definition of the main backscatter region. The exact contouring process, instead, made use of a combination of different grey level values (backscatter intensity), seafloor texture (e.g., bedforms, seafloor marks, shellfish beds, etc.), morphologies (from the Lidar bathymetric data), and sediment grain size characteristics.

\section{Comparison with RapidEye-TerraSAR-X seafloor classification}

Jung et al. (2015) performed a seafloor classification of the Norderney tidal flats, based on RapidEye (RE) and TerraSAR-X (TSX, multispectral satellite and synthetic aperture radar) data. The TSX data were used for outlining the water surface extension and the shellfish beds, which were then excluded from the sediment classification based on RE data (for details, Jung et al. 2015). Four RE images collected between 2010 and 2011 were classified, and the tidal flat area was segmented into sediment classes. One of the maps (June 2011) was used in this study for comparing the SSS vs. RE system ability of resolving the composition and the spatial distribution of the tidal flat sediments. In their research, Jung et al. (2015) were able to distinguish the shellfish beds and four sediment classes (mud, mixed sediments, wet sand, and dry sand). In order to be able to compare the SSSsediment classes with the ones defined by Jung et al. (2015), the amount of classes based on SSS-sediments were reduced accordingly. All the areas classified by Jung et al. (2015) as "water" were blanked in the SSSsediment classification and not taken into account for the final comparison.

\section{Geographic information system}

All the data were loaded on GIS software (QGis 2.7 and Global Mapper 15) for data visualization, analysis, bordering, and for the computation of the spatial statistics.

\section{Results}

\section{Morphology (Lidar data)}

Based on the areas marked as "water" in the Lidar data, the subtidal system covered about $25 \%$ of the entire study site (Fig. 2). 
Fig. 4 SSS mosaics of 2013 (left) and 2014 (right) in $1 \mathrm{~m}$ resolution. Red (2013) and orange (2014) lines correspond to the shellfish beds extension; green colors (dark green: 2013, bright green: 2014) correspond to the tidal drainage system (Riffgat channel and secondary channels). The regions corresponding to these classes were used for comparison. The adverse weather conditions (see Table 1) during the 2014 data collection severely influenced the data quality of the related SSS records, and the acoustic signal is disturbed by acoustic noise and artifacts. While the sharp changes in backscatter intensity are still visible (shellfish beds and drainage system), the gradual transitions among the intertidal flat deposits are overridden by the noise, making impossible a further subdivision of such region into classes. The small boxed areas zoom into the three main tidal system components: intertidal deposits (1a and $1 \mathrm{~b}$ ); shellfish beds ( $2 \mathrm{a}$ and $2 b)$; drainage system ( $3 a$ and $3 b$ )
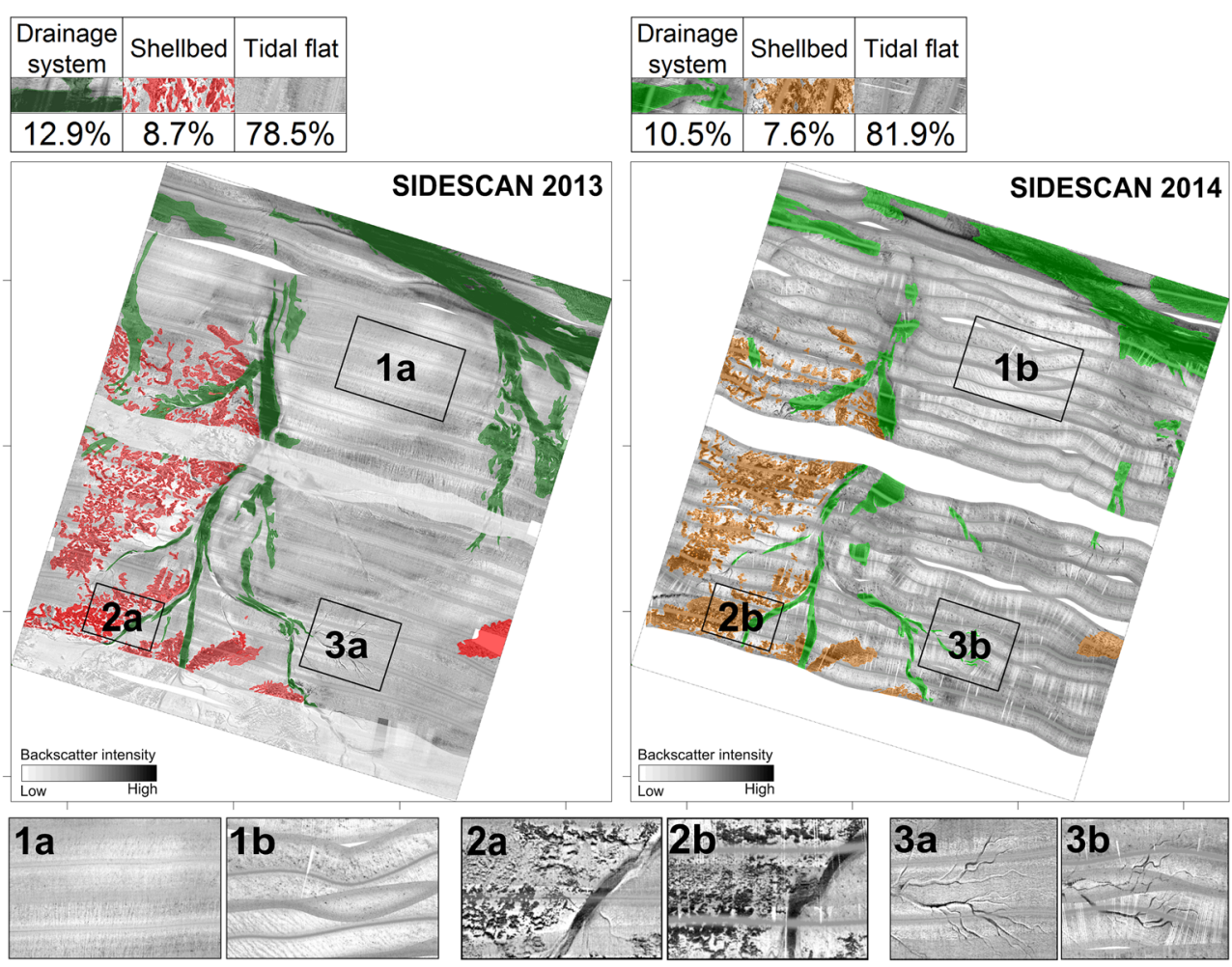

The Wagengat channel (Fig. 1) divided the area in two domains:

- A western region (transect T1 in Fig. 2), cut by four mainand several secondary gullies. The extensive presence of shellfish beds (identified by their patchy-like topographic roughness on the Lidar data) was the distinctive feature of this region. The northwest sandbank bordering the Riffgat channel (northern end of transect T1, Fig. 2) was the only area not covered by shellfish beds.

- An eastern region characterized by a smoother and less articulated morphology. The topography gently sloped northward $(0.03 \%$, transect T3 Fig. 2c) until the creek near to the station T35 (Fig. 2b; elevation difference: $0.25 \mathrm{~cm}$ ). In the central part, a depression marked the watershed between two drainage sub-systems (which streamed to the Wagengat and to the eastern secondary channel) and showed a rougher texture (irregular bedforms) than the surrounding areas. A slightly steeper slope $(0.09 \%)$ reached the max height of $-0.14 \mathrm{~m}$, where a sand flat (average slope: $0.02 \%$ ) bordered the Riffgat channel edge. This highest sector (average height: $0.23 \mathrm{~m}$ ) presented a sub-elliptical shape and a steeply slope into the Riffgat channel (average slope angle of $3.95 \%)$. The only shellfish bed present in the eastern region was located on its southeastern margin.

\section{Sediment grain size distribution}

Fine to very fine sediments characterized the research area (Fig. 3 and Table 2), ranging from sandy mud (mud content up to 80 weight $\%=\mathrm{w} \%$ ) to well sorted fine sand (fine sand > $94 \mathrm{w} \%$ ), with a content of coarser fractions generally negligible (only one sample with medium sand $>1 \mathrm{w} \%$ ). Sediments coarser than medium sand were not found. For the computation of the pie charts showed in Figs. 3 and 5, only three grain size fractions were used (mud, very fine sand, and fine sand), as the coarser fraction was largely absent or sub-represented (sediments $\geq$ medium sand $=0.1-1.4 \mathrm{w} \%$ ).

The western region (transect T1) showed the highest amount of mud (average mud content $>55 \mathrm{w} \%$ ) in correspondence to the presence of the large shellfish beds. A succession of muddy sand and sandy mud characterized the eastern region (transects $\mathrm{T} 2$ to $\mathrm{T} 5$ ), where a higher amount of fine fraction (muddy sediments) corresponded to the morphologically depressed areas (Figs. 3 and 5). Although a proper direct sampling was not possible inside the gullies (as they were mostly covered by water even during low tide), in-field observations allowed to characterize those sediments as a mixture of sand and shell debris, typically covered by a layer of soft muddy sediments. A sampling campaign carried out in the Riffgat channel in 2011 showed a sediment composition from sand (fine to 
Table 2 Sediment grain size distribution (in $\varphi$ intervals, Wentworth scale) and relative sediment classes (after Folk 1954)

\begin{tabular}{|c|c|c|c|c|c|c|c|c|c|c|}
\hline \multirow[b]{2}{*}{ N_UTM } & \multirow[b]{2}{*}{ E_UTM } & \multirow[b]{2}{*}{ Name } & \multirow{2}{*}{$\begin{array}{l}\text { Gravel } \\
G \\
\varphi<-1 \\
\%\end{array}$} & \multicolumn{5}{|l|}{ Sand } & \multirow{2}{*}{$\begin{array}{l}\text { Mud } \\
M \\
4 \leq \varphi \\
\%\end{array}$} & \multirow[b]{2}{*}{ Folk (1954) } \\
\hline & & & & $\begin{array}{l}V c S \\
-1 \leq \varphi<0 \\
\%\end{array}$ & $\begin{array}{l}C S \\
0 \leq \varphi<1 \\
\%\end{array}$ & $\begin{array}{l}M S \\
1 \leq \varphi< \\
\%\end{array}$ & $\begin{array}{l}F S \\
2 \leq \varphi<3 \\
\%\end{array}$ & $\begin{array}{l}V f S \\
3 \leq \varphi<4 \\
\%\end{array}$ & & \\
\hline $5,949,558$ & $383,700.4$ & $\mathrm{~T} 11$ & 0 & 0 & 0 & 0 & 2.6 & 30.5 & 66.8 & sM \\
\hline $5,949,731$ & 383,721 & $\mathrm{~T} 12$ & 0 & 0 & 0 & 0 & 3.1 & 30.7 & 66.2 & sM \\
\hline $5,949,852$ & $383,756.4$ & $\mathrm{~T} 13$ & 0 & 0 & 0 & 0 & 1.2 & 17.2 & 81.6 & sM \\
\hline $5,950,004$ & $383,767.8$ & $\mathrm{~T} 14$ & 0 & 0 & 0 & 0 & 8.3 & 25.3 & 66.4 & sM \\
\hline $5,950,157$ & $383,782.6$ & $\mathrm{~T} 15$ & 0 & 0 & 0 & 0 & 9.7 & 28.1 & 62.2 & sM \\
\hline $5,950,331$ & $383,779.1$ & T16 & 0 & 0 & 0 & 1.1 & 16.6 & 39.2 & 43.2 & $\mathrm{mS}$ \\
\hline $5,950,503$ & $383,807.8$ & $\mathrm{~T} 17$ & 0 & 0 & 0 & 1.1 & 94 & 4.5 & 0.3 & $\mathrm{~S}$ \\
\hline $5,949,506$ & $384,054.5$ & $\mathrm{~T} 21$ & 0 & 0 & 0 & 0 & 38.1 & 36.8 & 25.1 & $\mathrm{mS}$ \\
\hline $5,949,688$ & $384,067.7$ & $\mathrm{~T} 22$ & 0 & 0 & 0 & 0.1 & 68.6 & 25.7 & 5.6 & $\mathrm{~S}$ \\
\hline $5,949,845$ & $384,068.8$ & $\mathrm{~T} 23$ & 0 & 0 & 0 & 0 & 74.5 & 21.8 & 3.8 & $\mathrm{~S}$ \\
\hline $5,949,999$ & $384,116.5$ & $\mathrm{~T} 24$ & 0 & 0 & 0 & 0 & 39 & 40.3 & 20.7 & $\mathrm{mS}$ \\
\hline $5,950,163$ & $384,128.6$ & $\mathrm{~T} 25$ & 0 & 0 & 0 & 0.1 & 77.2 & 20.9 & 1.8 & $\mathrm{~S}$ \\
\hline $5,949,077$ & $384,147.7$ & $\mathrm{~T} 31$ & 0 & 0 & 0 & 0.1 & 8.9 & 22.6 & 68.4 & sM \\
\hline $5,949,237$ & $384,211.7$ & T32 & 0 & 0 & 0 & 0.3 & 47.9 & 14.8 & 36.9 & $\mathrm{mS}$ \\
\hline $5,949,496$ & 384,299 & $\mathrm{~T} 33$ & 0 & 0 & 0 & 0.1 & 34.5 & 29.8 & 35.6 & $\mathrm{mS}$ \\
\hline $5,949,676$ & $384,337.4$ & T34 & 0 & 0 & 0 & 0 & 66.8 & 26.7 & 6.5 & $\mathrm{~S}$ \\
\hline $5,949,875$ & $384,393.8$ & T35 & 0 & 0 & 0 & 0 & 13.7 & 38.9 & 47.4 & $\mathrm{mS}$ \\
\hline $5,950,192$ & $384,436.2$ & $\mathrm{~T} 36$ & 0 & 0 & 0 & 0.1 & 81.3 & 18.1 & 0.6 & $\mathrm{~S}$ \\
\hline $5,948,948$ & $384,505.1$ & $\mathrm{~T} 41$ & 0 & 0 & 0 & 0.2 & 58.9 & 21.5 & 19.5 & $\mathrm{mS}$ \\
\hline $5,948,972$ & $384,505.7$ & $\mathrm{~T} 42$ & 0 & 0 & 0 & 0.6 & 51.3 & 41.2 & 6.9 & $\mathrm{~S}$ \\
\hline $5,949,358$ & $384,504.2$ & $\mathrm{~T} 43$ & 0 & 0 & 0.1 & 0.8 & 34.9 & 23.1 & 41.1 & $\mathrm{mS}$ \\
\hline $5,949,562$ & $384,499.3$ & $\mathrm{~T} 44$ & 0 & 0 & 0 & 0.1 & 30.7 & 33.9 & 35.3 & $\mathrm{mS}$ \\
\hline $5,949,740$ & $384,493.8$ & $\mathrm{~T} 45$ & 0 & 0 & 0.5 & 0.9 & 84.1 & 12.3 & 2.2 & $\mathrm{~S}$ \\
\hline $5,949,787$ & $384,497.1$ & $\mathrm{~T} 46$ & 0 & 0 & 0 & 0 & 27.7 & 32.5 & 39.8 & $\mathrm{mS}$ \\
\hline $5,949,937$ & $384,489.8$ & $\mathrm{~T} 47$ & 0 & 0 & 0.1 & 0.2 & 15.6 & 41.2 & 42.9 & $\mathrm{mS}$ \\
\hline $5,950,047$ & $384,492.5$ & $\mathrm{~T} 48$ & 0 & 0 & 0 & 0 & 87 & 12 & 1.1 & $\mathrm{~S}$ \\
\hline $5,950,363$ & $384,515.7$ & $\mathrm{~T} 49$ & 0 & 0 & 0 & 0.1 & 92.2 & 7.2 & 0.5 & $\mathrm{~S}$ \\
\hline $5,949,385$ & $384,699.6$ & T51 & 0 & 0 & 0 & 1 & 37.3 & 28 & 33.7 & $\mathrm{mS}$ \\
\hline $5,949,382$ & $384,696.2$ & T51 & 0 & 0 & 0 & 0 & 25.1 & 20.5 & 54.4 & $\mathrm{sM}$ \\
\hline $5,949,660$ & $384,687.8$ & T53 & 0 & 0 & 0 & 0 & 32.6 & 28.3 & 39.1 & $\mathrm{mS}$ \\
\hline $5,949,797$ & $384,681.3$ & T54 & 0 & 0 & 0 & 0.6 & 87.5 & 10.7 & 1.2 & $\mathrm{~S}$ \\
\hline $5,949,844$ & $384,675.8$ & T55 & 0 & 0 & 0 & 0.1 & 16.1 & 33.4 & 50.4 & sM \\
\hline
\end{tabular}

very coarse) to gravel, with an average content of $6 \mathrm{w} \%$ of gravel and $14 \mathrm{w} \%$ of shell debris.

\section{Sidescan sonar 2013}

Compared with its larger spatial extent $(\sim 78 \%$ of the entire study site), the area presented gradual backscatter changes across a very limited amount of greyscale values (177-210: min-max of mean greyscale values, cf. greyscale histogram in Table 3), which could be further segmented in subclasses only at very large scale and by implementing Lidar and sediment information (see next paragraph). Sharp backscatter changes (boundaries) in the SSS mosaic, instead, were produced by a very few specific seafloor features (shellfish beds and tidal drainage system, i.e., channels and gullies), easy to be identified and delineated (Fig. 3a). Based on the backscatter data, the study site was therefore subdivided into three main morphological elements:

- $\quad$ shellfish beds (Fig. 4: red polylines in SSS 2013), dominant in the western region and only present in one bank in the eastern region. It corresponds to class 1 of the seafloor classification (see next paragraph). The greyscale 

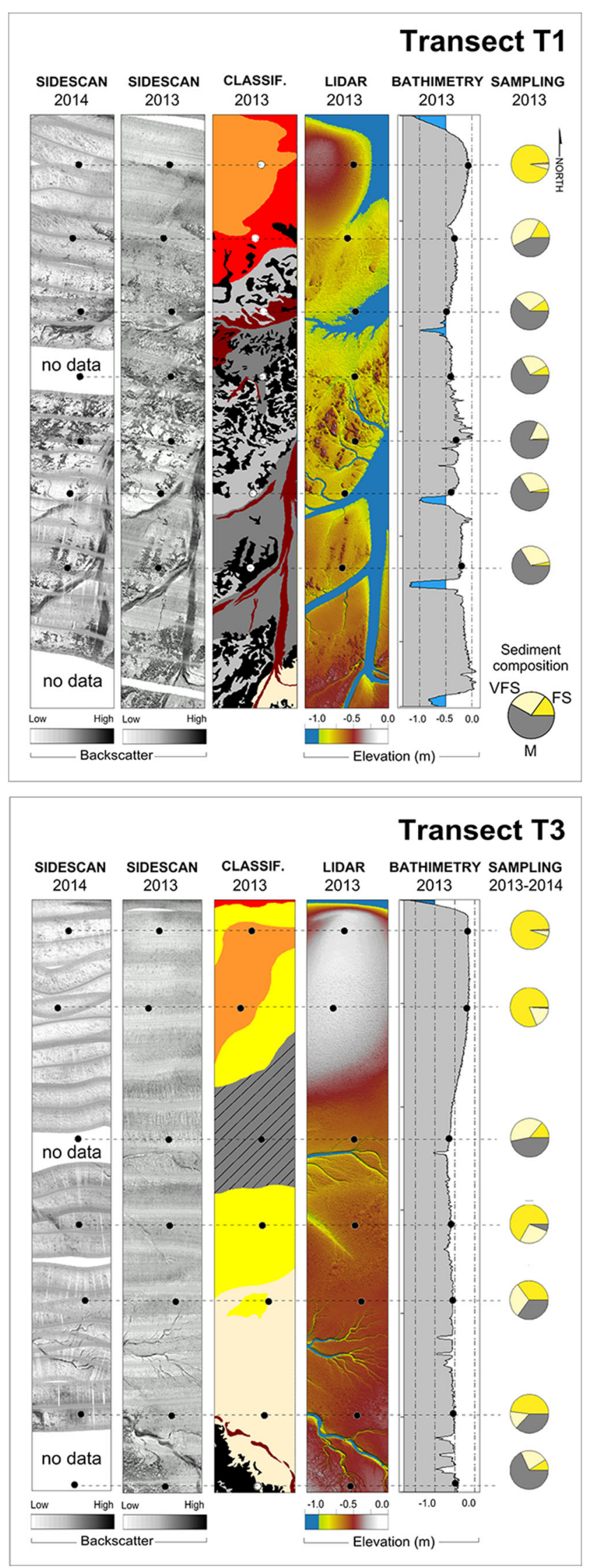

Fig. 5 Comparison of SSS backscatter data (2013 and 2014), seafloor classification, Lidar-based bathymetry, and sediment fractions (mud, very fine sand, and sand) along transects T1 and T3 (for the location of the transects, cf. Fig. 2). These two transects were chosen to best represent the high variability of sediments, backscatter, and topographic features in the western and eastern regions of the study site, dominated by the association shellfish-mud (T1, west of the Wagengat) and by the typical intertidal mixed flat-sand flat sequence (T3, east of the Wagengat). For the details about the seafloor classification, see Fig. 3 and the body text

histogram showed a bimodal distribution and a mean greyscale value lower than the average tidal flat deposit histograms (Table 3);

- tidal drainage system, (Fig. 4: dark green polylines in SSS 2013) corresponding to the Riffgat channel, the Wagengat secondary channel, and its equivalent on the eastern side; the Wagengat extended southward across the entire area and did not show a clear connection with the Riffgat. It includes class 9 and class 10 of the seafloor classification. The drainage system was characterized by the highest average backscatter values (= lowest mean greyscale values, classes 9 and 10, Table 3);

- tidal flat deposits, (Fig. 4), which covered most of the area and were characterized by greyscale backscatter values gradually fading into each other and within a very narrow average range (177-210, classes 2 to 8, Table 3 ). It corresponds to class 2 to 8 in the seafloor classification.

Bedforms (Fig. 3a, north-east corner) were observed at the margin of the area, in a dune field (average wavelength $6 \mathrm{~m}$ ) near the Riffgat channel. The dunes were not visible in the Lidar-based DTM, as the sector was covered by water during the data acquisition. The depressed area in the center of the western region (already identified in the Lidar data) presented a specific seafloor texture, with bedforms (mostly north-northeast/southsouthwest oriented, not regularly spaced) and seafloor marks.

\section{Seafloor classification}

The intertidal area presented gradational changes in the SSS backscatter intensity around a very narrow range of greyscale values. Nevertheless, differences in the backscatter intensity and in the seafloor texture were observed, especially at a large scale, where it was possible to distinguish sub-metric sized bedforms and seafloor patterns. The integration of the morphological information derived by the Lidar data was useful in setting up boundaries among the classes. The surface sediment results confirmed the definition of the classes and helped in the description of their characteristics. Based on the SSS 
Table 3 Summary of the sediment and backscatter characteristics for the 10 seafloor classes. Greyscale histograms (on the right): $X$-axis $=8$-bit greyscale values, from 0 (black) to 255 (white), corresponding to high and low backscatter intensities, respectively. $Y$-axis: number of counts per class (not the same scale for all the classes)

\begin{tabular}{|c|c|c|c|c|c|c|c|c|}
\hline Class $n$. & $\begin{array}{c}\text { Mean } \\
\text { mud } \\
\text { content }\end{array}$ & Class description & Class code & Coverage & $\begin{array}{c}\text { Mean } \\
\text { greyscale } \\
\text { value }\end{array}$ & $\begin{array}{c}\text { SSS backscatter } \\
\text { (detail) }\end{array}$ & & Greyscale histogram \\
\hline Class 1 & no data & Shellfish beds & SB & $10.1 \%$ & 146 & & $=$ & \\
\hline Class 2 & $71.6 \%$ & Mud & $M$ & $6.7 \%$ & 199 & & $\sum_{\substack{\infty \\
\infty}}$ & \\
\hline Class 3 & $65.7 \%$ & $\begin{array}{l}\text { Mud to Very fine } \\
\text { Sand }\end{array}$ & M-VFS & $9.2 \%$ & 191 & & $\equiv$ & \\
\hline Class 4 & $27.6 \%$ & $\begin{array}{l}\text { Mud to Very fine } \\
\text { Sand with bedforms }\end{array}$ & M-VFS (bd) & $9.0 \%$ & 186 & & $=$ & \\
\hline Class 5 & $37.6 \%$ & Mud to Fine Sand & M-FS & $15 \%$ & 194 & & $=\infty$ & \\
\hline Class 6 & $8.5 \%$ & $\begin{array}{l}\text { Very fine Sand to } \\
\text { Fine Sand }\end{array}$ & VFS-FS & $19.5 \%$ & 189 & & 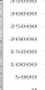 & \\
\hline Class 7 & $0.8 \%$ & Fine Sand & FS & $7.2 \%$ & 210 & & $=$ & \\
\hline Class 8 & $43.2 \%$ & $\begin{array}{l}\text { Fine Sand to } \\
\text { Medium Sand }\end{array}$ & FS-MS & $11.4 \%$ & 177 & & $=$ & \\
\hline Class 9 & $25.8 \%$ & Sand with shells & $\mathrm{S}(\mathrm{sh})$ & $8.8 \%$ & 130 & & 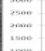 & \\
\hline Class 10 & $71.6 \%$ & $\begin{array}{c}\text { Sand with shells and } \\
\text { gravel }\end{array}$ & $S(\operatorname{sh~G)}$ & $3.2 \%$ & 81 & & $=$ & \\
\hline
\end{tabular}

backscatter intensity, on the seafloor texture and morphologies (SSS and Lidar data), and on the sediment composition and distribution, 10 classes were identified (Fig. 3, Table 3):

- Class 1, Shellfish bed: large banks of shellfish (mainly blue mussels and oysters), with size from $\sim 10$ to $38,000 \mathrm{~m}^{2}$. The class showed a greyscale histogram (with a bimodal envelope, Table 3) and a mean greyscale value (146), which differed significantly from all the other classes. Class 1 was dominant in the western region, while in the eastern region only a single shellfish bank was described and mapped. The presence of shellfish beds on the SSS data was consistent with the Lidar information, where the shellfish beds produced a specific topographic texture, more elevated $(0.4-0.5 \mathrm{~m})$ and rougher than the surrounding muddy and sandy areas.

- Class 2, Mud: mean mud content > $71 \mathrm{w} \%$. Class 2 occurred mainly in the western region, associated with the shellfish beds. If compared with the other intertidal flat classes (classes 3 to 8), class 2 showed a greyscale histogram shifted toward higher greyscale values (lower backscatter intensity).

- Class 3, Mud to Very fine Sand: mean mud content = $65.7 \mathrm{w} \%$. It showed a higher amount of sand, a smoother seafloor surface (SSS data) and higher backscatter intensity, if compared with class 2 . It was present mostly in the western region in association with classes 1 and 2 . In general, classes 3 to 7 showed comparable greyscale histograms and mean values, all within a very small range (177-210).

- Class 4, Mud to Very fine Sand with bedforms: average mud content lower than in class $3(27.6 \mathrm{w} \%$ and $65.7 \mathrm{w} \%$, respectively). Class 4 corresponded with the depressed area in the center of the eastern region, and presented a specific seafloor texture characterized by bedforms of different size and orientation.

- Class 5, Mud to Fine Sand: class 5 covered an area which constantly and gently sloped northward (average $0.04 \mathrm{w} \%)$. The three grain size fractions were almost 
equally distributed (mud: $37.6 \mathrm{w} \%$, very fine sand: $26.8 \mathrm{w} \%$, fine sand: $36.6 \mathrm{w} \%$ ). The classes 5 and 6 showed similar greyscale values and seafloor texture in the SSS data, although sporadic bedforms and seafloor marks were present in class 5 .

- Class 6, Very fine Sand to Fine Sand: the most significant differences respect to class 4 were represented by the mud content (which dropped from the $37.6 \mathrm{w} \%$ of class 5 to the $8.5 \mathrm{w} \%$ of class 6$)$ and by the presence of fine sand $(64.1 \mathrm{w} \%)$ as dominant fraction. The surface showed generally a smooth aspect on the SSS mosaic, only sporadically characterized by seafloor marks.

- Class 7, Fine Sand: corresponding to the most elevated areas of the study site (sand banks), which bordered the Riffgat from the south. The sediment composition was sand for $>99 \mathrm{w} \%$, with fine sand $>85 \mathrm{w} \%$. The seafloor within class 7 presented a smooth surface both in the Lidar and in the SSS data, with the highest mean greyscale value (210) among the intertidal-sediment classes.

- Class 8, Fine Sand to Medium Sand: characterized by the presence of medium sand $(1.1 \mathrm{w} \%)$ and a backscatter intensity significantly higher than class 7 . The class bordered the Riffgat channel and the north-western sandbanks and presented a few sporadic bedforms and seafloor marks. It showed the lowest mean greyscale value (177).

- Class 9, Sand with shells: together with class 10, it characterized the tidal drainage system (channels and gullies) and presented the highest backscatter intensity recorded in the area. Specifically, Class 9 referred to the secondary channels. The sediment analysis was based on only 2 samples (T54 and T55) with a high variance in composition. The sand content is $>74 \mathrm{w} \%$, with medium sand $>50 \mathrm{w} \%$ for T55. In-field observations showed a high amount of shell debris mixed with sandy sediments on the bottom of the secondary channels.

- Class 10, Sand with shells and gravel: it corresponded to the Riffgat channel and it showed a sharp change in backscatter intensity values respect to the surrounding regions. On the bottom of the Riffgat channel it was possible to recognize both regular bedforms and different morphological structures. Class 10 showed the lowest mean greyscale value (81, corresponding to the highest mean backscatter).

\section{Comparison sidescan sonar 2013 and 2014}

The SSS mosaics of 2014 showed a great difference in quality respect to the 2013 data (Fig. 4). The acoustic recordespecially in the intertidal region - was significantly affected by the noise, due to the adverse weather conditions. Attempts to filter or minimize the noise (enhancing the seafloor signature) did not succeed. Nevertheless, the three main morphological elements (shellfish beds, drainage system, and tidal flat deposits) could be recognized and mapped in SSS image of 2014. In its total amount, the area covered by each of these three components did not vary significantly in one-year time (Fig. 4).

The surface classified as drainage system showed limited variation in spatial coverage (from 12.0 to $10.5 \%$ ) and the main morphological changes were observed in the connection between the eastern secondary channel and the Riffgat, which was clearly visible in the 2013 and blurred 1 year later. Minor modifications occurred also in the geometry of some of the gullies (Fig. 4, box 3a and 3b), which presented meter-sized shifts and differences in shape.

The shellfish bed extension in the two mosaics did not change significantly from 2013 to 2014 (8.7\% and 7.6\%), and even isolated and meter-size shellfish patches could be detected in the 2014 dataset (Fig. 4, box 2a and 2b).

The main difference between the 2013 and 2014 mosaics was represented by the impossibility of subdividing the intertidal flat deposits into classes: the acoustic artifacts, in fact, strongly masked the information coming from the seafloor (Fig. 4, box 1a and 1b). As a consequence, a unique class was assigned for the intertidal region, where 7 classes were defined in the 2013 mosaic.

\section{Discussion}

\section{Seafloor classification}

The three main morphological components of the Lütetsburger tidal flat system (drainage network, intertidal deposits, and shellfish beds) were identified and mapped in both the SSS and in the Lidar datasets (Fig. 2). Although the SSS has a very limited ability in reconstructing the morphobathymetry of the seabed, in the study area it allowed the definition and delineation of the same morphological seafloor features recognized in the Lidar-DTM dataset and, in some cases, at a higher detail.

\section{Tidal drainage system}

The high backscatter mean values (Table 3) and the sharp contrast with the surroundings served as acoustic signature for contouring the tidal drainage system. Such high backscatter intensity was due to the presence of shell debris and gravel on the channels' bottom. The missing connection between the Wagengat and the Riffgat in the SSS 2013 mosaic (Fig. 3a, b) was likely due to a lack of coarse material. In fact the hydraulic section of the Wagengat channel was much broader in the connection to the Riffgat than in its southern part, where it cuts sharply through the intertidal flat sediments. As a result, the energy of the tidal flow is much lower at the Riffgat-Wagengat branching, and likely not enough to either remove the finer fractions (selecting the coarser material), or to transport and 
deposit coarser material and shell debris in that area. On the other hand, this result could be also related to the mobility of the sandy sediments, which-depending on energetic events - can temporarily cover and smooth the coarser fraction. The same effect can be observed where the Riffgat branches in its secondary channel (eastern region), by comparing the SSS mosaics of 2013 and 2014 (Fig. 4). The clear connection showed in 2013 disappeared in the 2014 dataset, where a lower backscatter area is still recognizable, without any distinctive border.

\section{Shellfish beds}

Shellfish beds (Class1, Fig. 3c) were clearly recognizable in the SSS datasets, representing the second most prominent acoustic features in both records. Similarly to the drainage system, the shellfish beds generated a unique acoustic signature on SSS data, with high backscatter intensity and a bimodal envelope of its greyscale histogram (Table 3). The bimodal distribution could be either due to the twofold nature of the seabed (shellfish patches and fine sediments trapped in between) resolved by the SSS in two slightly overlapping peaks (the second peak resembles the histograms of the other intertidal classes), or it could be the result of the scatter-shadow succession (high and low backscatter). The latter, in fact, depends on the specific geometry of the SSS system (side looking beams), the elevated reliefs of the shellfish beds, the operation conditions (water depth shallower than $1 \mathrm{~m}$ ), and the angle between the shellfish beds and the travel direction of the SSS, which produce streams of extremely high backscattering reefs (dark greyscale tones), followed by their related shadows (with low backscatter values, light greyscale tones).

Shellfish beds were also recognized as patchy-like topographic features in the Lidar bathymetry, more elevated $(0.4-0.5 \mathrm{~m})$ than the surrounding areas (Fig. 2). However, their spatial extension was different in the SSS and Lidar records (Fig. 6). In fact, the SSS backscatter was mainly influenced by the roughness associated with such communities, independently on the age and/or development stage of the shellfish beds. On the contrary, the topography (which plays the major role in generating the shellfish beds fingerprints on the bathymetric data) is strongly influenced by the development stage of these communities. The Lidar intensity data for the 2014 dataset were also tested, in regard to a small site $(20 \times 15 \mathrm{~m}$, Fig. $6 \mathrm{e})$, in order to check the sensitivity of the different remote sensing system in detecting and mapping the shellfish beds. The size of the reefs in the intensity data matched the one in the SSS image. On the other hand, the intensity pattern (which corresponds to the shellfish beds) occurred also in areas where those beds were not present (Fig. 6e, red dotted line). Sagawa et al. (2008) deployed a sidescan sonar for characterizing the seagrass distribution in near-to-shore areas, and used such classification for performing a supervised classification of satellite images. Similarly, as a future development, the possibility of performing high resolution seafloor classification on small testing areas by means of ground-truthed SSS, and to use the outcomes for training Lidar intensity and satellite classification algorithm should be proved.

\section{Tidal flat deposits}

The combination of shellfish beds (Class 1) and the related fine sediment deposits (Class 2-Mud, and Class 3-Mud to very fine sand) outlined a specific region (the western one), with distinctive biological, sedimentological, morphological, and geographical characteristics, which were sum up in transect T1 (Fig. 5). In this region, the shellfish beds acted as sediment traps for the finest fractions, slowing down the currents and allowing the sedimentation of muddy sediments, which are not removed by tidal currents. The primary production of fine organic material (fecal pellets) from the shellfish beds must be taken into account.

The remaining five classes (Class 4 to Class 8) represented a typical tidal flat succession, the sedimentological composition of which included a continuous mixture of three grain size fractions: clay, silt, and sand. The spatial distribution of these classes and their relationship with the morphology are sum up in transect T3, which crossed all of them (Fig. 5). The general decrease in mud content from Class 4 to Class 8 marked the transition from mixed flat (Class 4 to Class 6 ) to sand flat (Class 7 and Class 8). The mud content in Class 4 (27.6 w\%, lower than in Class 5, Table 3) was explained as a result of the two sediment samples (outliers) collected at the transition with Class 6 (T45, T48, cf. Fig. 2b and Fig. 3b). If excluded, the average mud content for Class 4 would have been of $38.0 \mathrm{w} \%$. Class 4 (Mud to very fine sand with bedforms) corresponded to the morphologically depressed area in the center of the eastern region. Despite its mud content ( $>40 \mathrm{w} \%$ ) exceeded the threshold defined by Reineck and Wunderlich (1968, modified by Flemming 2003) for a sand flat (mud $<5 \%$ ), Class 8 (fine sand to medium sand) was included in sand flat deposits. In fact, only one sediment sample was collected in the area.

The subdivision into five classes (Classes 4 to 8 ) was possible only integrating the sediment grain size analyses, the morphological information, and the backscatter texture. The interpretation had to take into account the time difference between the acoustic and the sediment data collection. The seafloor conditions recorded in the SSS data, in fact, could potentially not agree with the information provided by the grain size analysis, as the seafloor was reworked during the ebb or flood flow between two slack water intervals. 
Fig. 6 Detection of shellfish beds and patches by means of different remote sensing devices. SSS and Lidar data were exported at $0.5 \mathrm{~m}$ grid. Shellfish beds can be easily recognized and mapped both in the SSS and in the Lidar topographic data, although the extension of the banks is much more clear in the SSS datasets (even in the 2014, despite of the poor quality of the dataset). Similarly to the SSS backscatter, Lidar intensity could be used for the detection and mapping of shellfish beds, although similar intensity values and pattern are not univocally generated by the presence of such features: the area contoured with a dashed line present intensity values similar to the shellfish beds ones

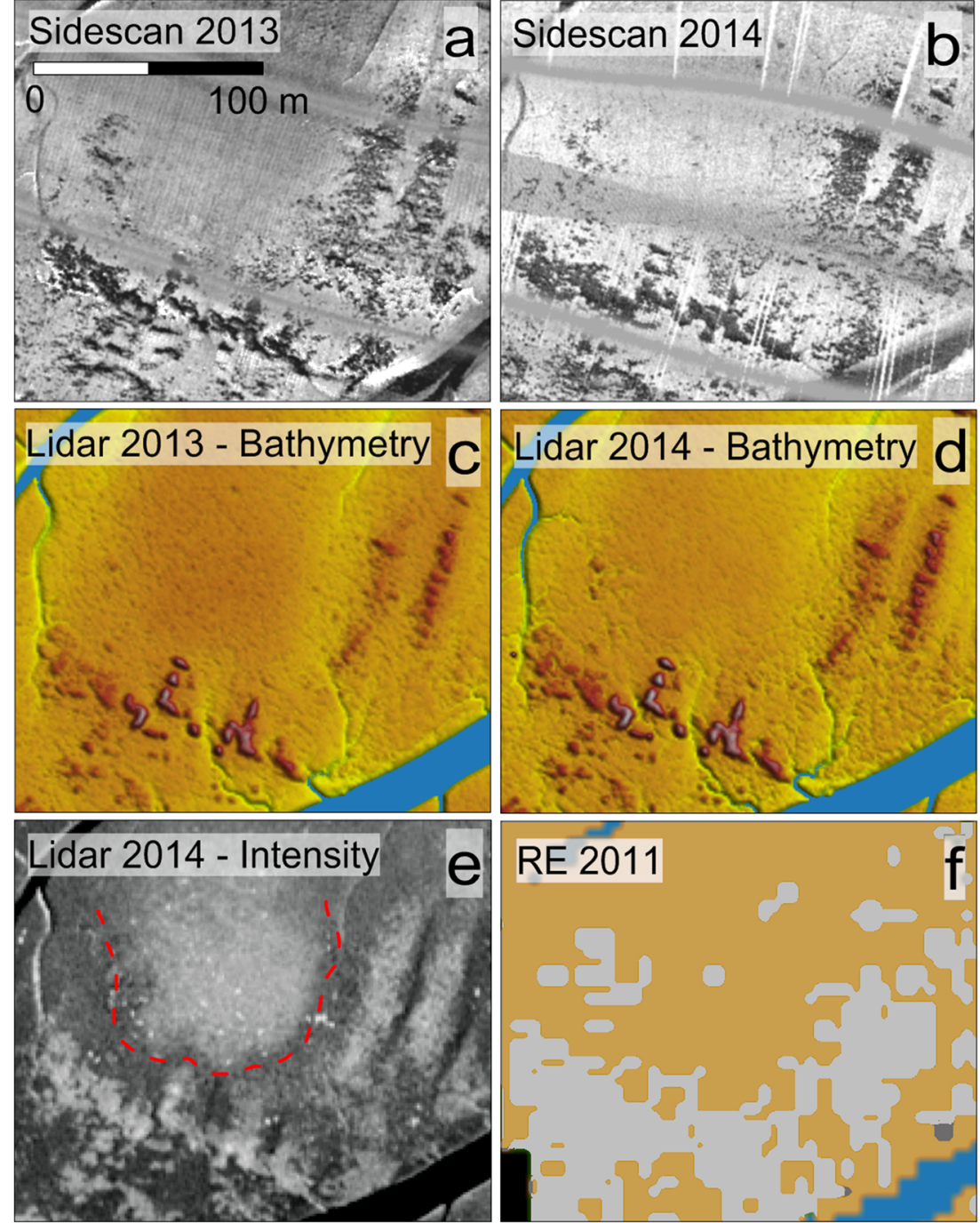

\section{Comparison sidescan sonar 2013 and 2014}

The weather seems to be the most impacting factor for the quality of the SSS data (Fig. 4). The sea conditions recorded in 2014 differed significantly from 2013 (Table 1): the maximum wave height $(1.2 \mathrm{~m})$ adversely affected the sonar movements (which could not be completely compensated in post-processing) and the seawater characteristics (more air bubbles and sediments in the water column). The effects were amplified in such extreme shallow conditions. The decreased signal-to-noise ratio and the presence of acoustic artifacts distorted the seafloor information. As a result, it was not possible to define any sub-class within the intertidal deposits. Nevertheless, the SSS sonar can be still considered a suitable and reliable tool for investigating the seafloor, if the main focus is to resolve the tidal system into its three main components (drainage network, shellfish beds, and tidal flat deposits, as expression of morphology, biology, and sediments).

\section{Comparison with RapidEye-TerraSAR-X seabed classification}

For the comparison with the classification performed by Jung et al. (2015) in 4 classes, the original number of 10 classes was decreased accordingly. Excluding the shellfish beds, in face, Jung and coauthors (Jung et al. 2015) divided the tidal flat deposits into four classes: mud, mixed sediments, wet sand, and dry sand, with reference to the EU Habitat Directive (Council Directive 92/43/EEC) for the sediment definition. The definition of littoral and sublittoral mixed sediments according to the European Environmental Agency (EUNIS) includes any kind of poorly sorted mixture of non-consolidated sediments, with grain size ranging from clay to gravel. Pebbles, cobbles, and boulder are also included among the mixes sediments, mainly depending on their relationship with other grain size fractions and on the observation scale. Within this frame, any kind of grouping or clustering of the seafloor classification classes was necessarily subjective, to some 
Fig. 7 Seafloor classification of the Lütetsburger area by means of a SSS, Lidar, and sediment data and $\mathbf{b}$ satellite data (RapidEYE$\mathrm{RE}$ and TerraSAR-X, Jung et al. 2015). The area covered with water in the RE classification was excluded from further computation. The 10 seafloor classes were grouped and reduced to four, in order to match the RE classification, and the corresponding coverage (in \%) was given for comparison
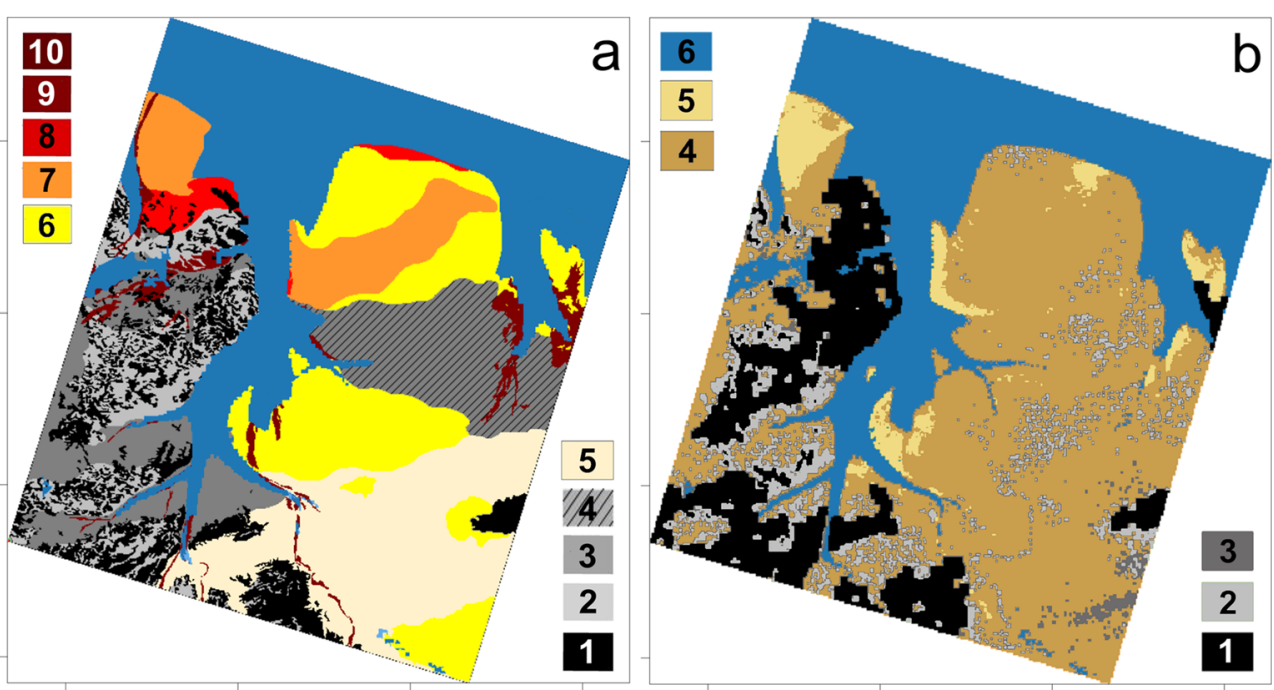

\begin{tabular}{|c|c|c|c|c|c|c|c|}
\hline \multicolumn{4}{|c|}{ Sidescan-Sediment classification } & \multicolumn{4}{|c|}{ RapidEye-TerraSAR-X classification } \\
\hline Class & $\%$ & & $\%$ & $\%$ & & $\%$ & Class \\
\hline$S(\operatorname{sh} G)$ & 0.0 & \multirow{2}{*}{$\begin{array}{c}\text { Coarse } \\
\text { sed. }\end{array}$} & \multirow{2}{*}{2.8} & \multirow{2}{*}{$\begin{array}{c}\text { no } \\
\text { corrispondence }\end{array}$} & \multirow{2}{*}{$\begin{array}{c}\text { Coarse } \\
\text { sed. }\end{array}$} & & \\
\hline$S(s h)$ & 2.8 & & & & & & \\
\hline$F S-M S$ & 1.4 & \multirow{3}{*}{ Sand } & \multirow{3}{*}{22.6} & \multirow{3}{*}{50.2} & \multirow{3}{*}{ Sand } & & \\
\hline FS & 6.3 & & & & & 3.6 & Dry Sand \\
\hline VFS-FS & 14.9 & & & & & 46.6 & Wet Sand \\
\hline$M-F S$ & 14.9 & \multirow{3}{*}{$\begin{array}{c}\text { Mixed } \\
\text { sed. }\end{array}$} & \multirow{3}{*}{30.6} & \multirow{3}{*}{0.7} & \multirow{3}{*}{$\begin{array}{c}\text { Mixed } \\
\text { sed. }\end{array}$} & \multirow{3}{*}{0.7} & \multirow{3}{*}{ Mixed Seds } \\
\hline M-VFS (bd) & 8.6 & & & & & & \\
\hline M-VFS & 7.1 & & & & & & \\
\hline$M$ & 6.4 & Mud & 6.4 & 6.0 & Mud & 6.0 & Mud \\
\hline $\operatorname{Sh} B$ & 9.7 & Shellbed & 9.7 & 15.1 & Shellbed & 15.1 & Mussel \\
\hline Water & 27.9 & Water & 27.9 & 27.9 & Water & 27.9 & Water \\
\hline
\end{tabular}

extent. In this comparison, Class $1(\mathrm{Sh})$ and Class 2 (M) found direct correspondence to the shellfish bed and mud classes in Jung et al. (Jung et al. 2015; Fig.7). The "muddy-sediment" classes (Class 3, M-VFS; Class 4, M-VFS (bd); Class 5, MFS) were grouped and compared with the "mixed sediment" class of Jung and coauthors (Jung et al. 2015), whereas the "sandy-sediment" classes (Class 6, VFS-FS; Class 7, FS; Class 8 , FS-MS) were grouped and compared with the "Sand" class in Jung et al. (2015). The remaining two coarse sediment classes (Class 9 and Class 10) had no correspondence in the RE classification, as they mainly occurred in the subtidal area (drainage network), which was excluded from the RE classification. The surface coverage was calculated for each of the new classes and the comparison was summarized in Fig. 7.

Whereas the shellfish bed class looked overestimated in the RE data, the area covered by mixed sediments approximated to zero. Based on these result, almost the entire study site should have been considered as sand flat, which was hard to explain considering its position in the backbarrier system and the sediment grain size results. The mixed sediment class covered the largest area in the seafloor classification (>30\% spatial coverage), immediately followed by the Sand class ( $>22 \% ;>25 \%$, if the values corresponding to Class 9 and
10 were added), which was instead the most relevant sediment class ( $>50 \%$ spatial coverage) in the RE classification. In contrast, the mud class showed similar spatial extension in both classifications, with a spatial coverage, which varied of $0.4 \%$.

In the comparison with the RE classification, the difference in resolution had to be taken into account: in fact, a single RE multispectral record is delivered in $25 \times 25 \mathrm{~km}$ tiles, with a $5.0 \mathrm{~m}$ pixel size and a $6.5 \mathrm{~m}$ resolution (ground sampling distance) at nadir, whereas the maximum resolution of the Starfish record was $<0.2 \mathrm{~m}$ (minimum size of a recognizable object). The semi-automatic process of picking up and interpolate the shellfish bed borders on TSX data, and to apply suck masks on the RE dataset produced a coarsening effect, which was likely responsible for the overestimation of the shellfish beds.

\section{Conclusions}

This very unique comparison of hydroacoustic SSS data, LIDAR, and satellite data of TerraSAR-X and Rapid Eye in this study could be summarize as follows: 
- The transition zone between intertidal and subtidal can be investigated by means of both multispectral (RapidEye, Lidar) and hydroacoustic (sidescan sonar) techniques. Rather than being an advantage, this may result in an increased uncertainty, because both approaches are limited by specific processes occurring in such transition zone (presence of water for the satellite and airborne systems; extreme shallow bathymetry and sensitivity to adverse weather conditions for the SSS).

- SSS showed to be a successful tool for classifying sediments and biological components (shellfish beds), with a resolution hardly achievable by most of the other sources, resulting to be a high performing system, in terms of effectiveness. The ability of detecting the lateral variability of sediments in gradational environments was proved. In this perspective, sidescan sonars can be used for mapping and monitoring the evolution of biotic and biotic components of a tidal system (e.g., the modifications in shellfish bed coverage) as long as weather/sea conditions allow collecting undisturbed data.

- The use of the SSS has the potential to be extended even further to the upper intertidal with a high effectiveness, although the efficiency would be much lower.

- SSS allows also the reconstruction of the main tidal morphological structures (channels, gullies, bedforms, etc.). If coupled with Lidar data, the classification can be improved and extended to the upper intertidal and in areas where boats would have no access. In this frame, it can be used for monitoring the morphological changes (sediment supply, sediment balance, etc.).

- The limited SSS swath allows the system to cover areas of $2-3.5 \mathrm{~km}^{2}$ per tide, which makes the system not very efficient, if compared with satellite or airborne remote sensing techniques.

- Satellite and airborne-based classifications present the advantage of an extremely large coverage (high efficiency), if compared with sidescan. They have been used quite successfully for mapping and monitoring biogenic features (reefs, mussel beds, etc.), whereas the detection of sedimentary regions is still impaired (lower effectiveness).

- As a future perspective, it is recommended to test the possibility to perform the sediment classification on small areas, based on sidescan sonar and sediment dataset. The outcomes could be used for training satellite The SSS-sampling technique could be performed on small areas, and the relative classification being used for training airborne-satellite remote sensing-based algorithm and classification processes.

Acknowledgments This study was partly founded by the German Research Foundation (DFG) within the INTERCOAST Project (an international research training group led by the University of Bremen, the Senckenberg Institute in Wilhelmshaven, and the University of Waikato), and partly financed by the Lower Saxony Ministry of Environment (MU Niedersachsen), Energy and Climate Protection and by the Ministry of
Science and Culture (MWK Niedersachsen), within the frame of the WIMO Project (Scientific monitoring concepts for the German Bight).

The authors would like to thank the crew of the RV Senckenberg, the colleagues from the Wadden Sea National Park, University of Hannover, University of Oldenburg, University of Osnabrück, who took part in the fieldwork activities, and, in particular, Jasmin Osterloh for her sampling efforts in the tidal flat. Many thanks to Astrid Raschke for the grain size analysis, and to Maik Wilsenack for his technical support.

We are particularly thankful to the Lower Saxony Water Management, Coastal Defence and Nature Conservation Agency (NLWKN Niedersachsen) for the access to the 2013 Lidar dataset. We also want to express our thanks to the anonymous reviewers, who contributed to improve the paper.

The data reported in this paper will be archived in Pangaea (www. pangaea.de).

Funding Information Open Access funding provided by Projekt DEAL.

Open Access This article is licensed under a Creative Commons Attribution 4.0 International License, which permits use, sharing, adaptation, distribution and reproduction in any medium or format, as long as you give appropriate credit to the original author(s) and the source, provide a link to the Creative Commons licence, and indicate if changes were made. The images or other third party material in this article are included in the article's Creative Commons licence, unless indicated otherwise in a credit line to the material. If material is not included in the article's Creative Commons licence and your intended use is not permitted by statutory regulation or exceeds the permitted use, you will need to obtain permission directly from the copyright holder. To view a copy of this licence, visit http://creativecommons.org/licenses/by/4.0/.

\section{References}

Adolph W, Jung R, Schmidt A, Ehlers M, Heipke C, Bartholomä A, Farke H (2017a) Integration of TerraSAR-X, RapidEye and airborne lidar for remote sensing of intertidal bedforms on the upper flats of Norderney (German Wadden Sea). Geo-Marine Letters 37:193-205. https://doi.org/10.1007/s00367-016-0485-Z

Adolph W, Schückel U, Chang SS, Jung R, Bartholomä A, Ehlers M, Kröncke I, Lehner S, Farke H (2017b) Monitoring spatiotemporal trends in intertidal bedforms of the German Wadden Sea in 20092015 with TerraSAR-X, including links with sediments and benthic macrofauna. Geo-Marine Letters 37:79-91. https://doi.org/10.1007/ s00367-016-0478-y

Adolph W, Farke H, Lehner S, Ehlers M (2018) Remote sensing intertidal flats with Terra-SAR-X. A SAR perspective of the structural elements of the tidal basin for monitoring the Wadden Sea. Remote Sensing 10. https://doi.org/10.3390/rs10071085

Badewien TH, Zimmer E, Bartholomä A, Reuter R (2009) Towards continuous long-term measurements of suspended particulate matter (SPM) in turbid coastal waters. Ocean Dynamics 59(2):227-238

Bartholomä A (2006) Acoustics bottom detection and seabed classification in the German Bight, southern North Sea. Geo-Marine Letters 26:177-184

Bartholomä A, Flemming B W (2007) Progressive grain-size sorting along an intertidal energy gradient.- In: Flemming BW, Hartmann D. (eds): From particle size to sediment dynamics. Proceeding of a Workshop, 15-18 April 2004, Hanse Institiute for Advanced Study, Delmenhorst (Germany). Sedimentary Geology (Spec. Issue), 202, 464-472, https://doi.org/10.1016/j.sedgeo.2007.03.010

Bartholomä A, Flemming BW, Delafontaine MT (2000) Mass balancing the turnover of mud and sand in the vicinity of an intertidal mussel bank in the German Wadden Sea (southern North Sea). In: Flemming BW, 
Delafontaine MT, Liebezeit G (eds) Muddy coast dynamics and resource management. Elsevier Science, Amsterdam, pp 85-106

Bartholomä A, Kubicki A, Badewien Th H, Flemming BW (2009) Suspended sediment transport in the German Wadden Seaseasonal variations and extreme events. Ocean Dynamics 59:213225. https://doi.org/10.1007/s10236-009—0193-6

Blott SJ, Pye K (2001) GRADISTAT: a grain size distribution and statistics package for the analysis of unconsolidated sediments. Earth Surf Proc Land 26(11):1237-1248

Brezina J (1979) Particle size and settling rate distributions of sand-sized materials. Conference paper, PARTEC: 2nd European symposium on particle characterization. Nürnberg, 24-26.09.1979, 1-47

Cambridge University Press (2014) Cambridge online dictionary. https:// dictionary.cambridge.org/dictionary/english

Carter RWG (1988) Coastal environments. An introduction to the physical, ecological and cultural systems of the coastlines. Academic press, New York $617 \mathrm{pp}$

Collier JS, Brown CJ (2005) Correlation of sidescan backscatter with grain size distribution of surficial sediment. Marine Geology 214:431-449

Degraer S, Moerkerke G, Rabaut M, Van Hoey G, Du Four I, Vincx M, Henriet JP, Van Lancker V (2008) Very-high resolution side-scan sonar mapping of biogenic reefs of the tube-worm Lanice conchilega. Remote Sensing of Environment 112:3323-3328. https://doi.org/10.1016/j.rse.2007.12.012

Delafontaine MT, Flemming BW, Bartholomä A (2000) Mass balancing the turnover of POC in mud and sand on a back-barrier tidal flat (southern North Sea). In: Flemming BW, Delafontaine MT, Liebezeit $\mathrm{G}$ (eds) Muddy coast dynamics and resource management. Elsevier Science, Amsterdam, pp 107-124

Dörjes J, Michaelis H, Rhode B (1986) Long-term studies of macrozoobenthos in intertidal and shallow subtidal habi-tats near the island of Norderney (East Frisian coast, Ger-many). Hydrobiologia 142:217-232

Flemming BW (2003) Flaser. In: Middleton GV (Ed) Encyclopedia of sediments and sedimentary rocks. Kluwer, Dordrecht, pp 282-283

Flemming B W (2012) Siliciclastic back-barrier tidal flats. In: Davis R A Jr, Dalrymple R W (eds), Principles of tidal sedimentology, 231-267, DOI: https://doi.org/10.1007/978-94-007-0123-6_10

Flemming BW, Ziegler K (1995) High-resolution grain size distribution patterns and textural trends in the backbarrier tidal flats of Spiekeroog Island (southern North Sea). Senckenbergiana Maritima 26:1-24

Folk RL (1954) The Distinction between grain size and mineral composition in sedimentary-rock nomenclature. J Geol 62(4):344-359

Gade M, Alpers W, Melsheimer C, Tanck G (2008) Classification of sediments on exposed tidal flats in the German Bight using multifrequency radar data. Remote Sensing of Environment 112:16031613. https://doi.org/10.1016/j.rse.2007.08.015

Gopal B, Junk WJ, Davis JA (2000) Biodiversity in wetlands: assessment, function and conservation. Volume 1. Backhuys Publishers, Leiden $353 \mathrm{pp}$

Heinrich C, Feldens P, Schwarzer K (2016) Highly dynamic biological seabed alterations revealed by side scan sonar tracking of Lanice conchilega beds offshore the island of Sylt (German Bight). Geo-Marine Letters 37(3):289-303. https://doi.org/10.1007/s00367-016-0477-z

Hinrichsen D (1998) Coastal waters of the world: trends, threats and strategies. Island press, Washington DC $275 \mathrm{pp}$

Holler P, Markert E, Bartholomä A, Capperucci R, Hass CH, Kröncke I, Mielk F, Reimers CH (2017) Tools to evaluate seafloor integrity: comparison of multi-device acoustic seafloor classifications for benthic macrofauna-driven patterns in the German Bight, southern North Sea. Geo-Marine Letters 37(2):93-109

ICES (2014) Report of the working group on marine habitat mapping (WGMHM), 19-23 may 2014, san Sebastian, Spain. ICES CM 2014/SSGSUE:07, 59
Joerdel O, Bartholomä A, Flemming BW (2002) Wave measurements using an ADCP?-The method and first results from the East Frisian Wadden Sea.-in Turla, T. (Eds.) (2002): hydro 2002- papers of the 17th hydrographic days 2002. The Hydrographic Special Publication 46:340-346

Jung R, Adolph W, Ehlers M, Farke H (2015) A multi-sensor approach for detecting the different land covers of tidal flats in the German Wadden Sea- a case study at Norderney. Remote Sensing of Environment 170:188-202

Markert A, Wehrmann A, Kröncke I (2010) Recently established Crassostrareefs versus native Mytilus-beds: differences in ecosystem engineering affects the macrofaunal communities (Wadden Sea of Lower Saxony, southern German Bight). Biological Invasions 12(1):15-32

Markert A, Esser W, Frank D, Wehrmann A, Exo KM(2013) Habitat change by the formation of alien Crassostrea-reefs in the Wadden Sea and its role as feeding sites for waterbirds. Estuarine Coastal Shelf Science 131:41-51

McLachlan A, Brown AC (2006) The ecology of sandy shores (second edition). Human Impacts 14:273-301

Müller G, Stelzer K, Smollich S, Gade M, Adolph W, Melchionna S, Kemme L, Geissler J, Millat G, Reimers HC, Kohlus J, Eskildsen K (2016) Remotely sensing the German Wadden Sea-a new approach to address national and international environmental legislation. Environmental Monitoring and Assessment 188:595. https:// doi.org/10.1007/s10661-016-5591-x

NOAA Coastal Services Center (2003) Pilot investigation of remote sensing for intertidal oyster mapping in coastal South Carolina: a methods comparison. NOAA/CSC/20514-PUB, $32 \mathrm{pp}$

Oost AP, Hoekstra P, Wiersma A, Flemming BW, Lammerts EJ, Pejrup M, Hofstede J, van der Valk B, Kiden P, Bartholdy J, van der Berg MW, Vos PC, de Vries S, Wang ZB (2012) Barrier island management: lessons from the past and directions for the future. Ocean \& Coastal Management 68:18-38

Park S E, Kim D H, Lee H S, Moon W, Wagner W (2010) Tidal wetland monitoring using polarimetric synthetic aperture radar. International Archives of the Photogrammetry, Remote Sensing And Spatial Information Sciences - ISPRS archives, 38

Rahnemoonfar M, Rahman F, Kline R, Greene A (2018) Automatic seagrass disturbance pattern identification on sonar images. IEEE Journal of Oceanic Engineering:1-10. https://doi.org/10.1109/JOE.2017.2780707

Reineck H-E, Wunderlich F (1968) Classification and origin of flaser and lenticular bedding. Sedimentology 11(1-2):99-104

Reineck HE, Singh IB (1980) Depositional sedimentary environments. Springer-Verlag, Berlin, p 551

Sagawa T, Mikami A, Komatsu T, Kosaka N, Kosako A, Miyazaki S, Takahashi M (2008) Mapping seagrass beds using IKONOS satellite image and side scan sonar measurements: a Japanese case study, (June 2013). International Journal of Remote Sensing 29:281-291

Schill S R, Porter D E, Coen L D, Bushek D, Vincent J (2006) Development of an automated mapping technique for monitoring and managing shellfish distributions: a final report. The NOAA/UNH cooperative Institute for Coastal and Estuarine Environmental Technology (CICEET), $91 \mathrm{pp}$

Schmidt A, Niemeyer J, Rottensteiner F, Soergel U (2012) Contextual classification of full waveform Lidar data in the Wadden Sea. Geoscience and Remote Sensing Letters, IEEE 11:1614-1618. https://doi.org/10.1109/LGRS.2014.2302317

Schmidt A, Rottensteiner F, Soergel U (2013) Water-land-classification in coastal areas with full waveform Lidar data. PFG 2(2013):71-81

Schmidt A, Adolph W, Klonus S, Ehlers M, Farke H, Soergel U (2019) Potential of airborne laser scanning data for classification of Wadden Sea areas. Advances in Geosciences

Shan J, Toth C K (2018) Topographic laser ranging and scanning: principles and processing. "Nd edition. CRC press, $638 \mathrm{pp}$

Stanev EV, Wolff J-O, Burchard H, Bolding K, Flöser G (2003) On the circulation in the East Frisian Wadden Sea: numerical modeling and 
data analysis. Ocean Dynamics 53:27-51. https://doi.org/10.1007/ s10236-002-0022-7

Stanev EV, Flemming BW, Bartholomä A, Staneva JV, Wolff JO (2007) Vertical circulation in shallow tidal inlets and back-barrier basins. Continental Shelf Research 27:798-831

Staneva J, Stanev E, Wolff J-O, Badewien T, Reuter R, Flemming BW, Bartholomä A, Bolding K (2009) Hydrodynamics and sediment dynamics in the German Bight: a focus on observations and numerical modelling. Continental Shelf Research 29(1):302-319

Streif H (1990) Das ostfriesische Küstengebiet: Nordsee, Inseln, Watten und Marschen. Reihe: Sammlung geologischer Führer, Bd. 57. Berlin Stuttgart, 1990

Udden JA (1914) Mechanical composition of clastic sediments. Geological Society of America Bulletin. 25(1):655-744

Van Beijma S, Comber A, Lamb A (2014) Random forest classification of salt marsh vegetation habitats using quad-polarimetric airborne SAR, elevation and optical RS data. Remote Sensing of Environment 149:118-129

Van der Wal D, Herman PMJ (2007) Regression-based synergy of optical, shortwave infrared and microwave remote sensing for monitoring the grain-size of intertidal sediments. Remote Sensing of Environment 111:89-106

van Overmeeren R, Craeymeersch J, Van Dalfsen J, Fey F, Heteren S, Erik M (2009) Acoustic habitat and shellfish mapping and monitoring in shallow coastal waters-sidescan sonar experiences in The Netherlands. Estuarine Coastal and Shelf Science 85:437448. https://doi.org/10.1016/j.ecss.2009.07.016

Walter F (1972) Zusammenhänge zwischen der Größe der ostfriesischen Seegaten mit ihren Wattgebieten sowie den Gezeiten und Strömungen. Jber. Forschungsstelle Küste 23:7-32

Wentworth CK (1922) A scale of grade and class terms for clastic sediments. Jour. Geol. 30:377-392

Winter C (2017) Monitoring concepts for an evaluation of marine environmental states in the German Bight. Geo Marine Letters 37(2):75-78

Publisher's note Springer Nature remains neutral with regard to jurisdictional claims in published maps and institutional affiliations. 